\title{
Ride Comfort Improvement of a Semi-active Vehicle Suspension Based on Hybrid Fuzzy and Fuzzy-PID Controller
}

\begin{abstract}
Ahmed O. BASHIR, Xiaoting RUI*, Jianshu ZHANG
Institute of Launch Dynamics, Nanjing University of Science and Technology Nanjing, 210094, China mecheng5120@yahoo.com, ruixt@njust.edu.cn (*Correspondingauthor), zhangjs_nust@sina.com

Abstract: The development of vehicles providing maximum drive comfort and handling stability is one of the design targets for car manufacturers. This paper proposes a hybrid fuzzy and fuzzy-PID (HFFPID) controller for a semi-active quarter-car with three degrees of freedom utilizing a magneto-rheological (MR) shock absorber. The control objective is to amend the ride quality of the vehicle. The proposed controller comprises a fuzzy-self-tuned proportional-integral-derivative (FSTPID) controller, a fuzzy-logic controller (FLC) and a fuzzy selector (FS). Based on the error between the output and its set point, the fuzzy selector selects which controller should play the greatest effect on the control system. The effectiveness of the proposed control strategy is analysed through simulations involving excitations for a bump road and a random road profile in time domain. The results show that the HFFPID controller has the best performance in reducing the car body acceleration, suspension working space and seat acceleration response compared with the uncontrolled as well as FLC-and HFPID controlled-cases. Hence, the best ride quality response is provided by the HFFPID controller as compared to all the other suspension systems considered in this paper.
\end{abstract}

Keywords: 3DOF quarter car, Ride-comfort, MR damped semi-active suspension, Hybrid fuzzy and fuzzy PID.

\section{Introduction}

The suspension system normally has a great effect on vehicle handling, safety and on the driver's experience by keeping the vehicle occupants comfortable. The design of vehicle suspension systems is an active research field in automotive industry (Du \& Zhang, 2007). Most regular suspensions utilize passive springs to lower responsive impact and vibrations. However, such suspension elements are passive in nature in the sense that, once implemented, the suspension system cannot accommodate to the variety of road surfaces on which it must operate.

As compared to an active suspension control, semi-active suspension (SAS) can offer both the stability of a passive suspension and the control effect of an active suspension without requiring external energy. Moreover, SAS can adjust its damping force in real time according to the controller requirements, which are usually based on vehicle suspension dynamics. Therefore, over the past decades, SAS systems have received considerable attention in the fields of vehicle applications (Yin et al., 2016). Often magnetorheological dampers (MRD) damper is utilized as promising semi-active device in SAS because it can change its viscosity continuously and produce the controllable damping force using a MR fluid. Control technology is the key issue in the study of MR damped semi-active suspensions. However, the moderate utilization of MR dampers for control is hampered by their characteristic hysteretic and extremely nonlinear dynamics. Hence, the development of suitable control methods which can take over the novel attributes of the MR dampers to achieve better ride comfort and stability, is a challenging perspective.

Recently, a wide variety of control methods have been reported for the usage in the vehicle suspension system domain such as e.g. Skyhook control (Guo et al., 2013), adaptive optimal control (Wang, 2018) and adaptive back-stepping control (Pang et al., 2019). On the other hand, (Oliveira et al., 2017) staged a numerical analysis of a fuzzy (FLC)-based control for a semi-active vehicle suspension system. (Mustafa et al., 2019) proposed model-free adaptive fuzzy logic control (MFAFLC) for a half-car active suspension system. (Khodadadi \& Ghadiri, 2018) developed a self-tuning PID controller based on FLC to improve the performance of a half-car active suspension system (HCASS). In the past years, for MR-damped semi-active suspension system various control strategies have been introduced and assessed by many researchers to improve the dynamics of nonlinear suspensions (Ying et al., 2003, Rashid et al., 2007, El-Kafafy et al., 2012). (Shanfa \& Kongkang, 2006) designed a switching control strategy between a PID and a Fuzzy system in a semi-active suspension system. The Fuzzy PID control technique reduced the vertical acceleration (VA) and provided robust performance when compared to the individual Fuzzy and PID control 
strategies. (Paksoy et al., 2014) examined a SelfTuning Fuzzy Logic controller (STFLC) for the goal of vibration reduction in a full vehicle semi-active suspension system (VSASS) with magneto-rheological damper. Simulation results showed that STFLC can effectively reduce the vehicle vibration compared to uncontrolled and Fuzzy Logic controlled suspension systems. (Hu et al., 2017) developed the hybrid fuzzy and the fuzzy PID (HFPID) control to suppress semi-active suspension vibrations by applying a magneto-rheological damper based on the hyperbolic-tangent model. Simply summarizing, the above-mentioned literature with respect to HFPID control, the ride comfort and vehicle maneuverability can be improved in some sense since vehicle vibration can be reduced. However, these controllers impose certain limitations due to the uncertainties of system parameters. Thus a hybrid of fuzzy-PID does not perform well, because when the MR damped vehicle suspension system parameters change, this will require new adjustment of the PID gains.

To improve the ride comfort in a semi-active vehicle system equipped with a MR damper, a hybrid control technique based on fuzzy and a fuzzy self-tuned PID (HFFPID) controller is designed. The control technique comprises three parts: a fuzzy logic controller, a fuzzy self-tuned PID (FSTPID) controller and a fuzzy selector (FS), which Shows the merits of the Fuzzy logic and PID control schemes. The designed controller bears two major advantages: the strengths of both fuzzy and fuzzy-PID controllers are benefited while the hybrid controller suitably performs with uncertainties of nominal parameters of the suspension system. The primary contribution of this paper lies in the application of a fuzzy combination of fuzzy and fuzzy self-tuning PID controllers. A quarter car model with MR damper with three degrees of freedom (3DOF) is formulated for each uncontrolled, fuzzy controlled, HFPID controlled as proposed by (Singh \& Aggarwal, 2017) and HFFPID controlled systems. The model is examined for two kinds of excitations, namely those generated by a bump road and random road profiles, by using Simulations are carried out by Matlab/ Simulink software. Simulation results for different controllers are compared with each other with regard to car body acceleration (BAC), suspension working space (SWS), and seat acceleration (SAC) responses.
The rest of the article is organized as follows: Both the mathematical model of the $3 \mathrm{DOF}$ quarter car and a Magneto-rheological shock absorber are explained in Section 2. The approach to control is outlined in section 3 . The designed control strategies are applied to the model of the quarter car system and the simulation results and comparison study are presented in detail in Section 4. Conclusions are presented in Section 5.

\section{The Dynamic Modeling of the System}

\subsection{Quarter-car Model}

A quarter-car model with MR damper assembled in the primary suspension system is shown in Figure 1. The model represents a real system with adopted parameters to passenger seat mass, sprung as well as un-sprung mass $\left(m_{1}, m_{2}, m_{3}\right)$, primary and secondary stiffness coefficients $\left(k_{1}, k_{2}\right)$, primary and secondary damping coefficients $\left(c_{1}\right.$, $\left.c_{2}\right)$, and tyre stiffness $\left(k_{t}\right)$. Passenger seat, sprung mass and car body displacement are described by $\left(z_{1}, z_{2}, z_{3}\right)$, whereas $z_{r}$ stands for road input amplitude. In case of semi-active behavior of suspension system, the MR shock absorber is in charge of generating an additional controllable damping force $f_{a}$. This model is adopted for studying vertical dynamics of car systems by ignoring vehicle roll and pitch dynamics. The governing dynamical equations of the three degree-of-freedom system can be derived from Newton's 2nd law of motion as

$$
\begin{gathered}
m_{1} \ddot{z}_{1}=-c_{2}\left(\dot{z}_{1}-\dot{z}_{2}\right)-k_{2}\left(z_{1}-z_{2}\right), \\
m_{2} \ddot{z}_{2}=c_{2}\left(\dot{z}_{1}-\dot{z}_{2}\right)+k_{2}\left(z_{1}-z_{2}\right)- \\
c_{1}\left(\dot{z}_{2}-\dot{z}_{3}\right)-k_{1}\left(z_{2}-z_{3}\right)-f_{a}, \\
m_{3} \ddot{z}_{3}=c_{1}\left(\dot{z}_{2}-\dot{z}_{3}\right)+k_{1}\left(z_{2}-z_{3}\right)- \\
k_{t}\left(\mathrm{z}_{3}-\mathrm{z}_{r}\right)+f_{a},
\end{gathered}
$$

Defining the state vector as

$$
\begin{aligned}
x & =\left[\begin{array}{llllll}
x_{1} & x_{2} & x_{3} & x_{4} & x_{5} & x_{6}
\end{array}\right]^{T} \\
& =\left[\begin{array}{llllll}
z_{1}-z_{2} & z_{2}-z_{3} & z_{3}-z_{r} & \dot{z}_{1} & \dot{z}_{2} & \dot{z}_{3}
\end{array}\right]^{T},
\end{aligned}
$$

Based on equations (1) -(3), the state equation of the system is the following:

$$
\left\{\begin{array}{l}
\dot{x}(t)=A x(t)+B u(t)+D w(t) \\
y=C x(t)
\end{array}\right.
$$


where

$$
A=\left[\begin{array}{cccccc}
0 & 0 & 0 & 1 & -1 & 0 \\
0 & 0 & 0 & 0 & 1 & -1 \\
0 & 0 & 0 & 0 & 0 & 1 \\
\frac{-k_{2}}{m_{1}} & 0 & 0 & \frac{-c_{2}}{m_{1}} & \frac{c_{2}}{m_{1}} & 0 \\
\frac{k_{2}}{m_{2}} & \frac{-k_{1}}{m_{2}} & 0 & \frac{c_{2}}{m_{2}} & \frac{-\left(c_{1}+c_{2}\right)}{m_{2}} & \frac{c_{1}}{m_{2}} \\
0 & \frac{k_{1}}{m_{3}} & \frac{-k_{t}}{m_{3}} & 0 & \frac{c_{1}}{m_{3}} & \frac{-c_{1}}{m_{3}}
\end{array}\right],
$$$$
B=\left[\begin{array}{llllll}
0 & 0 & 0 & 0 & \frac{-1}{m_{2}} & \frac{1}{m_{3}}
\end{array}\right]^{T}, \quad \mathrm{u}(\mathrm{t})=\left[f_{M R}\right]
$$$$
D=\left[\begin{array}{llllll}
0 & 0 & -1 & 0 & 0 & 0
\end{array}\right]^{T}, w(t)=\left[\dot{z}_{r}\right]
$$$$
\text { and } C=\left[\begin{array}{llllll}
0 & 1 & 0 & 0 & 0 & 0 \\
0 & 0 & 0 & 1 & 0 & 0 \\
0 & 0 & 0 & 0 & 1 & 0
\end{array}\right] \text {. }
$$

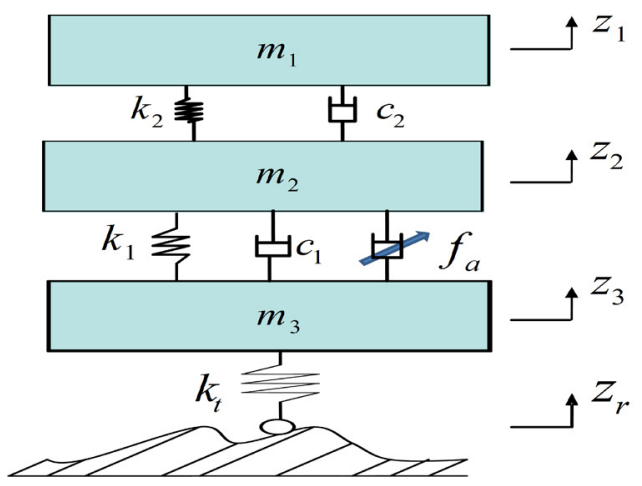

Figure 1. Quarter-car model

\subsection{Dynamic Model of MR Shock Absorber}

The 'Modified Bouc-Wen Model' shown in Figure 2 is a typical dynamic damper model, which is used in this work to depict the behavior of the MR damper as described by (Wen, 1976). The model includes diverse springs and dashpots to simulate the damper's dynamic characteristics. The accumulator stiffness is symbolized by a spring with invariant value $k_{D 1}$, the damping at high velocities is denoted by $c_{D 0}$. A dashpot with damping $c_{D 1}$ is introduced in the model to simulate the hysteresis loop at low frequencies. An extra spring with constant $k_{D 0}$ is placed into the model to control the stiffness for large velocities. The initial displacement due to the accumulator stiffness is $x_{0}$. For given signals $v$ and $x_{D}$, the force $f_{a}$ can be predicted using the following equations (Spencer Jr et al., 1997):

$$
\begin{aligned}
& f_{a}=c_{D 1} \dot{y}+k_{D 1}\left(x_{D}-x_{0}\right), \\
& \dot{y}=\frac{1}{c_{D 0}+c_{D 1}}\left(\alpha z+c_{D 0} \dot{x}+k_{D 0}\left(x_{D}-y\right)\right), \\
& \dot{z}=-\gamma\left|\dot{x}_{D}-\dot{y}\right||z|^{n-1} z-\left(\dot{x}_{D}-\dot{y}\right)\left(\beta|z|^{n}-A\right),
\end{aligned}
$$

where $y$ is inner displacement, $x_{D}$ is a damper displacement and variable $z$ is an evaluation parameter. The voltage $\alpha$ utilized depends on the current driver and can be formulated as follows

$$
\left\{\begin{array}{l}
\alpha=\alpha_{a}+\alpha_{b} u \\
c_{D 0}=c_{0 a}+c_{0 b} u \\
c_{D 1}=c_{1 a}+c_{1 b} u
\end{array}\right.
$$

where $u$ represents the output of a first order filter given as follows

$\dot{u}=-\eta(u-v)$.

In equation (8), $\eta$ is $u$ filter time constant and $v$ is a voltage input of the filter. The parameters including $c_{0 a}, c_{0 b}, c_{1 a}, c_{1 b}, \alpha_{a}, \alpha_{b}, \gamma, \beta, A$ and $n$ have to be adjusted. The parameter values listed in Table 1, have been adjusted based on (Lai \& Liao, 2002). Equations (5) -(9) are used to simulate the model. The input and output of the MR shock absorber are voltage $v$ and damper force $f_{a}$ respectively. The hysteresis behavior of the MR-fluid damper is demonstrated in Figure 3 , where an excitation displacement $x_{D}$ of $25 \mathrm{~mm}$ triggered with $1.97 \mathrm{~Hz}$ frequency is employed to the MR-damper, and the voltages applied are $0,0.5,1.0,1.5$ and $2 \mathrm{~V}$, respectively. It can be observed that as the voltage increases, the corresponding damping force increases as well.

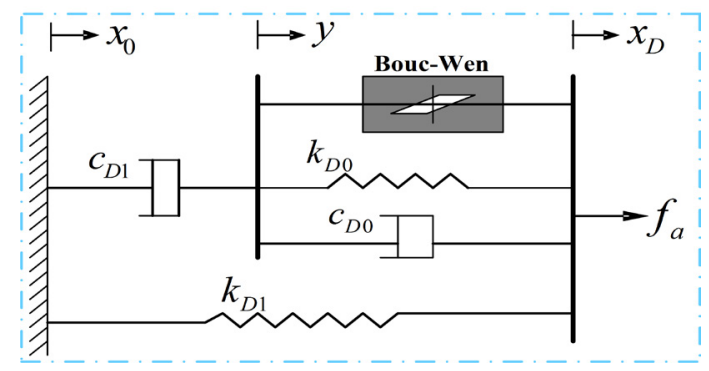

Figure 2. MR damper model

Table 1. Modified Bouc-Wen model parameters

\begin{tabular}{|l|l|l|l|}
\hline Symbol & Value & Symbol & Value \\
\hline$c_{0 a}$ & $784 \mathrm{~N} . \mathrm{s} / \mathrm{m}$ & $\alpha_{a}$ & $12441 \mathrm{~N} / \mathrm{m}$ \\
\hline$c_{0 b}$ & $1803 \mathrm{~N} . \mathrm{s} / \mathrm{Vm}$ & $\alpha_{b}$ & $38430 \mathrm{~N} / \mathrm{Vm}$ \\
\hline$k_{D 0}$ & $3610 \mathrm{~N} / \mathrm{m}$ & $\gamma$ & $136320 \mathrm{~m}-2$ \\
\hline$c_{1 a}$ & $14649 \mathrm{~N} . \mathrm{s} / \mathrm{m}$ & $\beta$ & $2059020 \mathrm{~m}-2$ \\
\hline$c_{1 b}$ & $34622 \mathrm{~N} . \mathrm{s} / \mathrm{Vm}$ & $A$ & 58 \\
\hline$k_{D 1}$ & $840 \mathrm{~N} / \mathrm{m}$ & $n$ & 2 \\
\hline$x_{0}$ & $0.0245 \mathrm{~m}$ & $\eta$ & $190 \mathrm{~s}-1$ \\
\hline
\end{tabular}




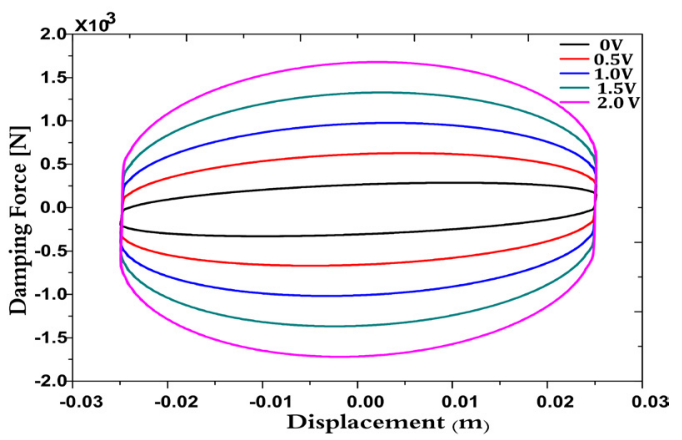

Figure 3. Damping force vs. displacement

\subsection{Control Objectives of Suspension System}

The designing control objective of the suspension system could be to minimize the root mean square (RMS) of the body acceleration(BAC) to obtain the best riding comfort, i.e., $\min B A C=\min \left\{R M S\left(\ddot{z}_{2}\right)\right\}$. An alternative control objective is to minimize the seat acceleration (SAC), i.e., $\quad \min S A C=\min \left\{R M S\left(\ddot{z}_{1}\right)\right\}$.Additionally the suspension working space (SWS) should be limited in the permitted dynamic deformation, i.e., $S W S=R M S\left(\mathrm{z}_{2}-z_{3}\right)$. To meet these control requirements, an efficient control is required.

\section{Controller Design}

The block diagram of the controlled MR damped vehicle suspension system is shown in Figure 4. The whole control system consists of two parts: a system controller that uses the dynamic responses of the plant to calculate the desired damping force $f_{d}$ according to FLC, FSTPID and HFFPID controllers; and the damper controller that predicts the voltage $v$ applied to the damper in order to track its actual force $f_{a}$ to the desired force $f_{d}$ . Equations (5) -(9) are used to estimate $f_{a}$ and implemented along with the state equation (4) for the car model. A brief description is provided in the following subsections.

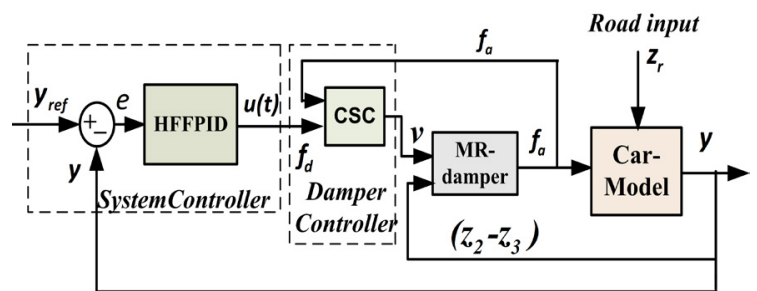

Figure 4.MR-damped vehicle suspension control block diagram

\subsection{PID Controller}

The scheme of the PID controller is very simple and effective. It is the most common form of feedback. PID controllers are today found in all areas where control is used (Johnson \& Moradi, 2005). The definition of PID control is as follows:

$u_{P I D}=k_{p} e(t)+k_{i} \int e(t) \cdot d t+k_{d} \frac{d}{d t} e(t)$,

where $u_{P I D}$ is the control variable, and $k_{p}, k_{i}$ and $k_{d}$ are control gains for the proportional, integral and derivative control action, respectively. The control error $e=y_{\text {ref }}-y$, where is the difference between reference value $y_{\text {ref }}$ and plant output $y$. Appropriate parameter tuning is a desirable feature of the PID controller (Muniraj et al., 2017). The right choice of the control gains is very significant to achieve favorable control performance of dynamic systems, especially when semi-active dynamic systems involve magnetorheological fluid dampers.

\subsection{Fuzzy Logic Controller}

Fuzzy controller features two input and one output variables. The error $(e)$ between the car-body $(\mathrm{CB})$ velocity and its reference value is one of the inputs, the other is the change rate of the error $(\dot{e})$ between the $\mathrm{CB}$ acceleration and its set point. The desired damping force $f_{d}$ is the output variable. The seven linguistic variables selected to describe the input and output variables are as follows: negatively big (NB), negatively medium (NM), negatively small (NS), zero (ZR), positively small (PS), positively medium (PM), and positively big (PB). In this work, triangular membership functions (MFs) to input and the output variables are applied in the range of $[-1,1]$ see Figure 5. Actual intervals of variables are decided by the scaling factors $q_{1}, q_{2}$ and $q$, respectively, which are chosen by human search with trial and error procedure. The fuzzy controller scheme is presented in Figure 6.

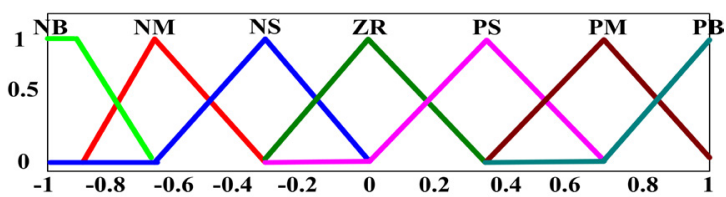

Figure 5. Input and the output variable MFs.

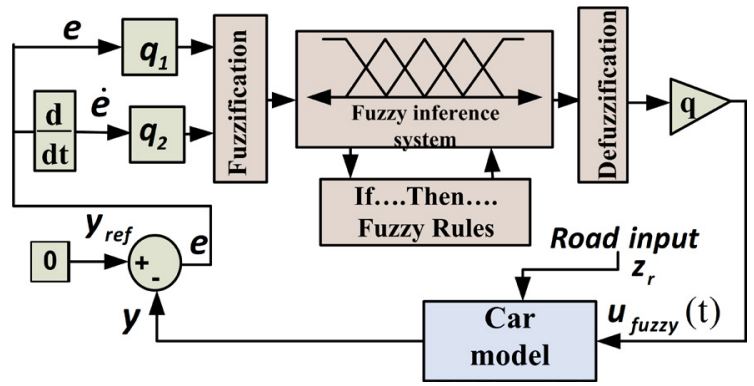

Figure 6. Fuzzy controller scheme 
The Fuzzy Logic control rules are in the form of

IF $e=R_{i} \& \dot{e}=d R_{j}$ Then $V=V(i, j)$,

where corresponding fuzzy control rules are presented in Table 2. For instance, one of the possible rules is that if $e$ is NS and $\dot{e}$ is $\mathrm{PB}$, then $u_{f u z z y}$ is $\mathrm{PM}$. This rule can be indicated as follows: if the error $e$ is low, the reference value is about the actual car body velocity (CBV). However, a positive big value of change rate $\dot{e}$ of the error shows that the $\mathrm{CBV}$ rapidly approaches the reference value, when the car body acceleration (CBA) is comparatively large. Therefore, the controller output ought to have a positive medium value to prevent overshoot. The Mamdani technique is chosen as fuzzy inference method, and the centroid method is used for defuzzification, which converts the linguistic variables $u_{\text {fuzzy }}$ into numerical data.

Table 2. Order of fuzzy controller rules

\begin{tabular}{|c|c|c|c|c|c|c|c|}
\hline$\dot{e} / e$ & NB & NM & NS & ZR & PS & $\mathrm{PM}$ & $\mathrm{PB}$ \\
\hline & & & & & & NS & ZR \\
\hline$M$ & $\mathrm{TM}$ & $\mathrm{IM}$ & M & NM & $1 v_{3}$ & ZR & PS \\
\hline IS & JM & NM & NM & NS & $\mathrm{ZH}$ & PS & $\mathrm{PI}$ \\
\hline $\mathrm{ZR}$ & JM & NM & NS & ZR & & PM & PN \\
\hline PS & $\mathrm{NM}$ & NS & ZR & PS & PM & PM & PN \\
\hline PM & NS & ZR & PS & PM & PM & PM & P \\
\hline $\mathrm{PB}$ & $7 \mathrm{P}$ & PS & PM & PB & PM & PM & PI \\
\hline
\end{tabular}

\subsection{Fuzzy Self-tuned PID Controller}

The fuzzy self-tuning PID controller employs the combination of PID and fuzzy algorithms. The coefficients of the conventional PID controller are not always tuned for the nonlinear plant with unpredictable parameter variations. Hence, it is necessary to automatically tune the three parameters $k_{p}, k_{i}$ and $k_{d}$ of $u_{P I D}$ controller using a fuzzy tuner (Zhang et al., 2004, Song \& Liu, 2006). The structure of the fuzzy self-tuning PID controller is illustrated in Figure 7. There are two inputs to fuzzy inference, i.e., error $e$ and derivative of error $\dot{e}$, and three outputs with PID controller parameters $k_{p}^{\prime}, k_{i}^{\prime}$ and $k_{d}^{\prime}$. A Mamdani type is applied as structure of fuzzy inference with some modifications to obtain the best value for $k_{p}, k_{i}$ and $k_{d}$. Suppose the variable ranges of the PID control parameters are $\left[k_{p \min }, k_{p \max }\right]$, $\left[k_{i \min }, k_{i \max }\right]$ and $\left[k_{d \min }, k_{d \max }\right]$ where $k_{d} \in[0,500]$, $k_{i} \in[0,500]$ and $k_{d} \in[0,1]$ was determined based on simulations to obtain a feasible rule basis with high inference efficiency. These parameters can be normalized in the interval $[0,1]$ by

$$
\begin{aligned}
& k_{p}^{\prime}=\frac{k_{p}-k_{p_{\min }}}{k_{p_{\max }}-k_{p_{\min }}}=\frac{k_{p}}{500}, \\
& k_{i}^{\prime}=\frac{k_{i}-k_{i_{\min }}}{k_{i_{\max }}-k_{i_{\min }}}=\frac{k_{i}}{500}, \\
& k_{d}^{\prime}=\frac{k_{d}-k_{d_{\min }}}{k_{d_{\max }}-k_{d_{\min }}}=k_{d} .
\end{aligned}
$$

Hence, from equations (12)-(14), one can obtain $k_{p}=500 k_{p}^{\prime}, k_{i}=500 k_{i}^{\prime}$ and $k_{d}=k_{d}^{\prime}$.

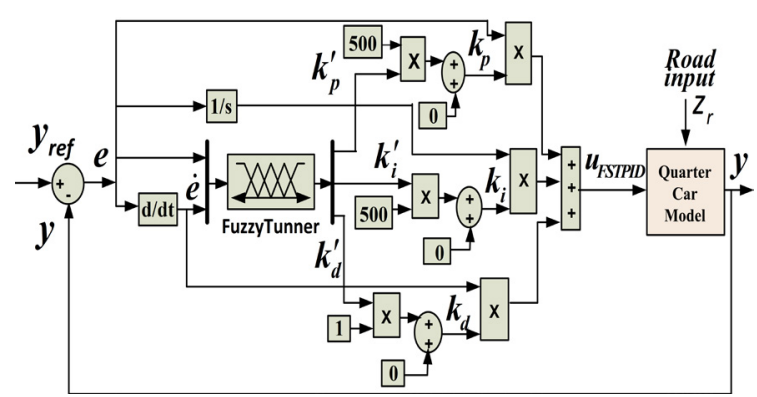

Figure 7. Fuzzy self-tuned PID controller

The linguistic variables for input and output variables are assigned as negative $(\mathrm{N})$, zero $(\mathrm{ZR})$ and positive $(\mathrm{P})$. The associate membership functions (MFs) are depicted in Figures 8(a) and 8 (b), respectively, where the data for input and output side are kept in the interval of $[-1,1]$ and $[0$, 1], respectively. The corresponding fuzzy control rule basis are shown in Table 3. Each pair $(e ; \dot{e})$ determines the output values corresponding to $k_{p}^{\prime}$, $k_{i}^{\prime}$, and $k_{d}^{\prime}$. For instance, one of the possible rules is that if $e$ is $\mathrm{N}$ and $\dot{e}$ is $\mathrm{P}$, then $k_{p}^{\prime}$ is $\mathrm{P}, k_{i}^{\prime}$ is $\mathrm{N}$ and $k_{d}^{\prime}$ is $\mathrm{N}$.
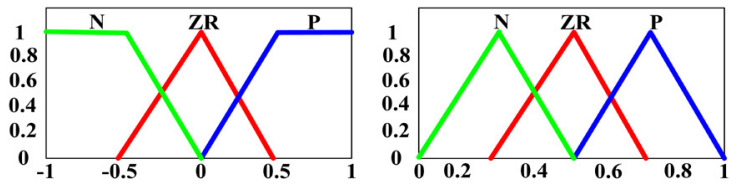

$$
\begin{array}{ll}
e \text { and } \dot{e} & \text { (b) } k_{p}^{\prime}, k_{i}^{\prime} \text { and } k_{d}^{\prime}
\end{array}
$$

Figure 8. Fuzzy tuner MFs of (a) inputs and (b) outputs 
Table 3. Rule base for $k_{p}^{\prime}, k_{i}^{\prime}$ and $k_{d}^{\prime}$

\begin{tabular}{|c|c|c|c|c|}
\hline \multirow{2}{*}{\multicolumn{2}{|c|}{$k_{p}^{\prime}, k_{i}^{\prime}, k_{d}^{\prime}$}} & \multicolumn{3}{|c|}{$\dot{e}$} \\
\hline & & $\mathrm{N}$ & ZR & $\mathrm{P}$ \\
\hline \multirow{3}{*}{$e$} & $\mathrm{~N}$ & ZRNN & ZRNN & PNN \\
\hline & ZR & PZRZR & ZRNN & ZRNN \\
\hline & $P$ & PPP & ZRPN & NPN \\
\hline
\end{tabular}

\subsection{Hybrid Fuzzy and Fuzzy-PID Controller}

A hybrid fuzzy PID controller owes its effectiveness to the advantages of both the fuzzy and PID controller. In addition, the gain adaptation of PID by means of a fuzzy tuner is used to ameliorate the controller. The control structure comprises of three parts as shown in Figure 9: a fuzzy self-tuned PID controller, a fuzzy controller and a fuzzy selector. Based on the fuzzy rules and depending on the error between the output and its set point value, the fuzzy selector determines, in a suitable way, when and how to switch the controller. If the output value of the system is far from the set point, the fuzzy controller will have the greatest effect on the control system. Likewise, when the output value is around the set point value, the fuzzy self-tuned PID controller will also have the most prominent effect on the system as compared to the fuzzy controller. One should have noticed that the fuzzy self-tuned PID controller has a higher exactness near the set point (Dequan et al., 2012).

As demonstrated in Figure 9, the inputs of the fuzzy selector are $e$ and $\dot{e}$, and the fuzzy lingual variables of inputs are N, ZR and P. The output of the fuzzy selector is the fuzzy control coefficient $L_{\text {fuzzy }}$ lingual variables $\mathrm{P}$ and $\mathrm{PB}$, where rules are presented in Table 4. The corresponding membership functions are illustrated in Figures 10. The adaption constants of both the PID and the fuzzy controller are $L_{1}$ and $L_{2}$, respectively. Furthermore, $L_{1}+L_{2}=1$. Hence, the output of the HFFPID controller is given by the following expression:

$$
u(t)=\left(L_{1} L_{f u z z y} u_{F S T P I D}(t)+L_{2} L_{f u z z y} u_{f u z z y}(t)\right),
$$

The design procedure of the proposed hybrid fuzzy and fuzzy-PID controller can be summarized as follows:

(i) Design the fuzzy logic controller as in subsection 3.2. (ii) Design the fuzzy self-tuned PID controller as in subsection 3.3.

(iii) Design the fuzzy selector using $e$ and $\dot{e}$.

(iv) Compute the final control output $u(t)$ from equation (15). Concerning the stability issue, it has been mentioned by (Zimmermann, 2011) that the stability analysis appears somehow inadequate for fuzzy controllers. They are implicitly supposed to be robust since they are based on the human experience. And when the PID controller is placed within the loop, the stability feature should be related to the PID controllers.

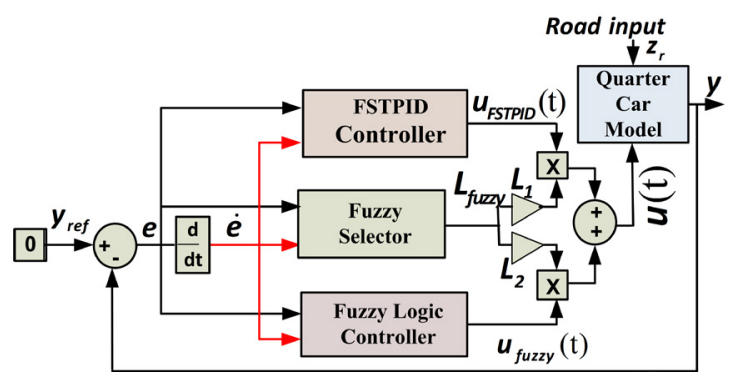

Figure 9. HFFPID control structure

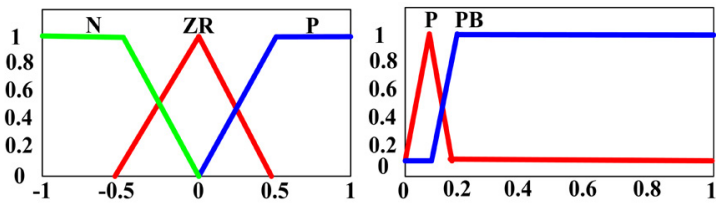

(a) $e$ and $\dot{e}$

(b) $L_{f u z z y}$

Figure 10. MFs of the fuzzy selector for (a) inputs and (b) output

Table 4. Fuzzy rules for fuzzy selector

\begin{tabular}{|c|c|c|c|c|}
\hline \multirow{2}{*}{$L_{\text {fuzzy }}$} & \multicolumn{3}{|c|}{$\dot{e}$} \\
\cline { 3 - 5 } & $\mathrm{N}$ & $\mathrm{ZR}$ & $\mathrm{P}$ \\
\hline \multirow{3}{*}{$e$} & $\mathrm{~N}$ & $\mathrm{P}$ & $\mathrm{P}$ & $\mathrm{P}$ \\
\cline { 2 - 5 } & $\mathrm{ZR}$ & $\mathrm{PB}$ & $\mathrm{P}$ & $\mathrm{PB}$ \\
\cline { 2 - 5 } & $\mathrm{P}$ & $\mathrm{P}$ & $\mathrm{P}$ & $\mathrm{P}$ \\
\hline
\end{tabular}

\subsection{MR-damper Controller}

In this paper, a continuous state controller (CSC) is used to find the input voltage ${ }_{v}$ applied to the MR damper such that its actual force $f_{a}$ closely tracks the desired damping force (system controller output force) $f_{d}$. The command voltage $v$ can vary continuously between minimum and maximum values of 0 and $V_{\max }$, respectively, according to the rule (Lam \& Liao, 2003).

$v(\xi)= \begin{cases}V_{\max } & \text { for } \xi>V_{\max } \\ V_{\min } & \text { for } \xi<V_{\min } \\ \xi & \text { otherwise }\end{cases}$ 
where $\xi=G\left(f_{d}-H f_{a}\right) \operatorname{sgn}\left(f_{a}\right)$ with gains $H$ and $G$. The values of $G, H$ and $V_{\max }$ were set to be $0.0038 \mathrm{~V} / \mathrm{N}, 1$ and $2 \mathrm{~V}$,respectively, as in (Lam \& Liao, 2003).

\section{Numerical Simulations}

To evaluate the ride comfort of the quarter car model, the RMS values of body acceleration (BAC), suspension working space (SWS) and seat acceleration (SAC) are considered as essential performance criteria that determine the ride comfort peculiar to the vehicle. Simulation is performed in the time domain for MR-passive and controlled semi-active quarter car systems with FLC, HFPID and HFFPID controllers. The parameters for the 3DOF vehicle model in Figure 1 are chosen as follows: $m_{1}=75 \mathrm{~kg}, m_{2}=320 \mathrm{~kg}$, $m_{3}=50 \mathrm{~kg}, \quad k_{1}=30000 \mathrm{~N} / \mathrm{m}, \quad k_{2}=7500 \mathrm{~N} / \mathrm{m}$, $k_{t}=210,000 \mathrm{~N} / \mathrm{m}, c_{1}=1500 \mathrm{KN} /(\mathrm{m} / \mathrm{s})$, and $c_{2}=750 \mathrm{~N} /(\mathrm{m} / \mathrm{s})$. respectively. The model is excited by two types of road inputs: bump input (BI) and random input (RI) to demonstrate the control performance of the proposed controller.

\subsection{Type 1: Bump Road Excitation}

The bump profile is mathematically described by (Choi \& Kim, 2000) as

$x_{r}=\left\{\begin{array}{cc}a\left(1-\cos \left(\omega_{r}(t-0.5)\right)\right), & \text { for } 0.5 \leq t \leq 0.5+d_{b} / V_{c} \\ 0, & \text { otherwise }\end{array}\right.$

where $a$ is the half bump amplitude, $d_{b}$ is the bump width, $V_{c}$ is the car velocity and $\omega=2 \pi V_{c} / d_{b}$. The values are adjusted based on (Choi and Kim, 2000). The resulting displacement of the road input signal under bump excitation is shown in Figure 11 . The time histories of $\left(z_{2}-z_{3}\right), \ddot{z}_{2}$ and $\ddot{z}_{1}$ responses are illustrated in Figure 12. For controlled semi-active suspension in the case of FLC, HFPID and HFFPID controllers, the comparison of the actual values of the damping control force produced by a MR damper for the various controllers is provided in Figure 13, and the input control voltage is shown in Figure 14. The damper control force shows a similar variation trend, which means that the modified
Bouc-Wen model of MR damper can precisely track the desired control force. According to Figure 14, the input voltage signal in case of the HFFPID controller is relatively higher due to the high actual damping force supplied.

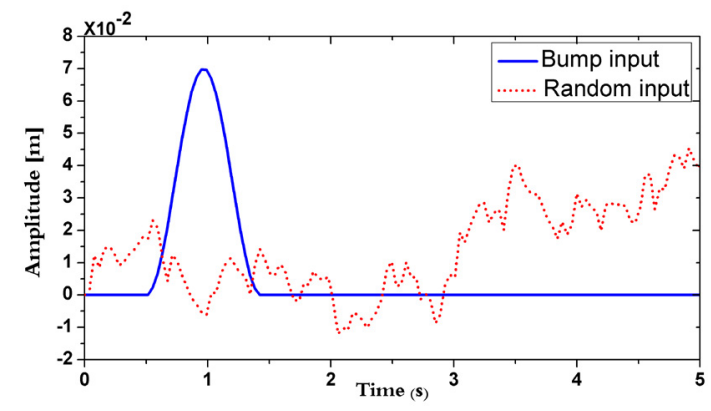

Figure 11. Road input signals

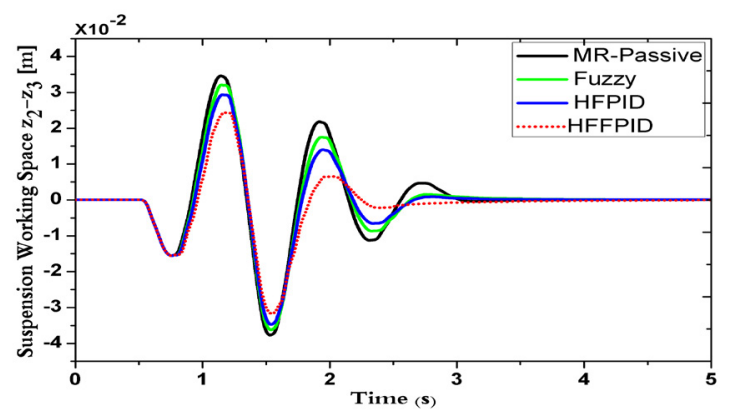

(a)

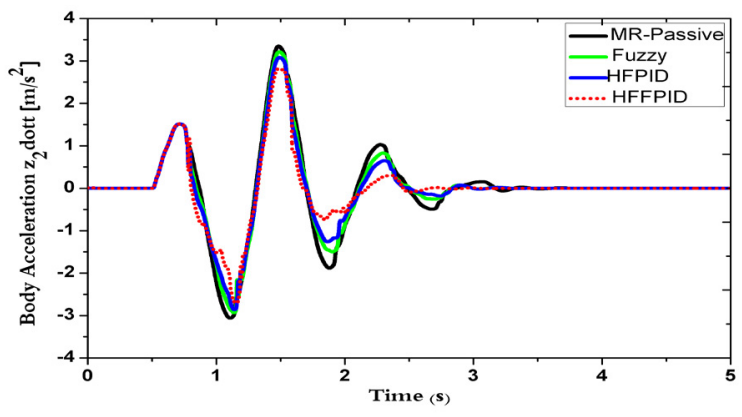

(b)

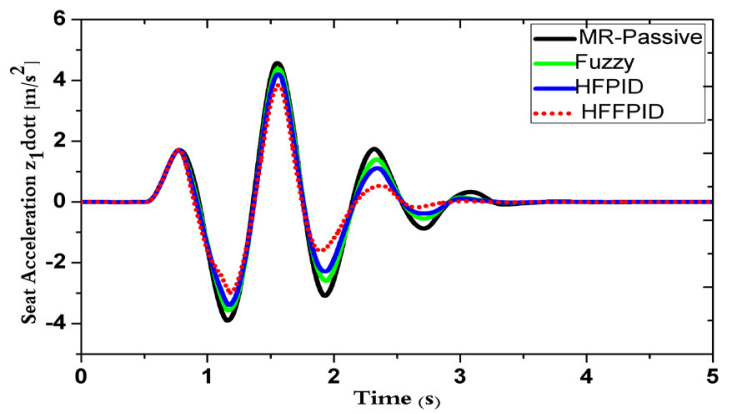

(c)

Figure 12. The time response of the system under BI excitation (a) SWS, (b) BAC and (c) SAC 


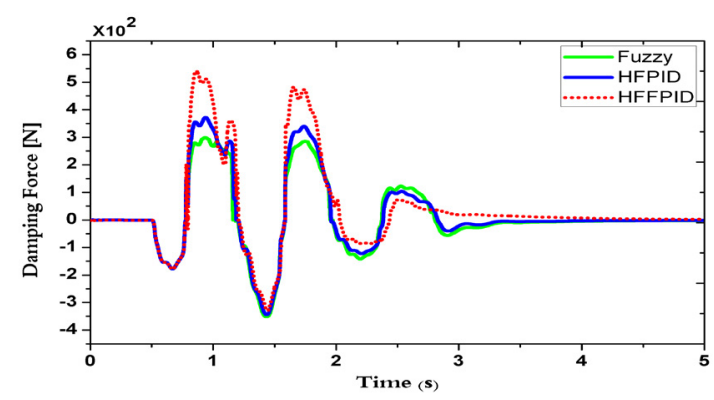

Figure 13. Damping force for BI

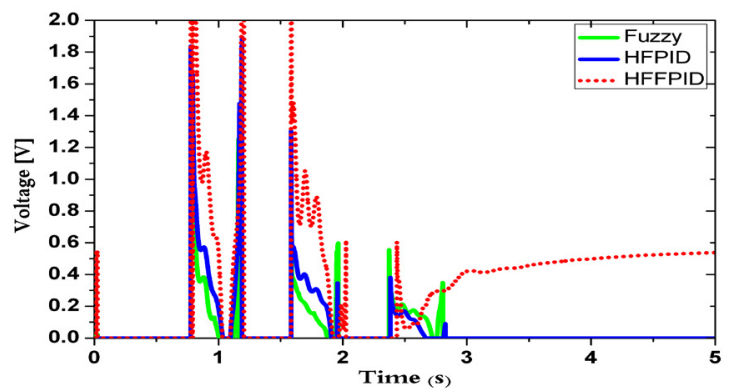

Figure 14. Input voltage for BI

Figure 15, shows a comparison of the peak-to -peak (PTP) values of the controlled semi-active suspension system using HFFPID with FLC controller, HFPID controller and MR passive suspension systems. Their relevant values of improvement percentages are shown in Table 5. From these results it is obvious that the semiactive vehicle suspension system controlled by HFFPID has a superior performance. It provides the best ride comfort response out of all suspension systems considered this paper.
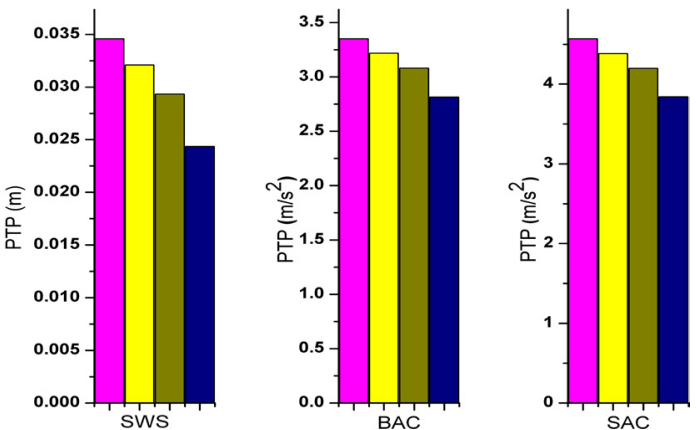

Figure 15. The PTP values of SWS, BAC and SAC

Table 5. Percentage Reduction of the PTP values of SWS, BAC and SAC for BI

\begin{tabular}{|c|c|c|c|}
\hline PTP & $\begin{array}{c}\text { HFFPID } \\
\text { with respect } \\
\text { to MR-assive }\end{array}$ & $\begin{array}{c}\text { HFFPID } \\
\text { with respect } \\
\text { to Fuzzy }\end{array}$ & $\begin{array}{c}\text { HFFPID } \\
\text { with respect } \\
\text { to HFPID }\end{array}$ \\
\hline SWS & $29.55 \%$ & $24.06 \%$ & $16.91 \%$ \\
\hline BAC & $15.99 \%$ & $12.52 \%$ & $8.60 \%$ \\
\hline SAC & $15.97 \%$ & $11.86 \%$ & $8.53 \%$ \\
\hline
\end{tabular}

\subsection{Type2: Random road excitation}

In order to validate the effectiveness of the HFFPID controller, a second type of road excitation is considered, that is the random road excitation which is presumed as a vibration signal coherent and usually specified as a white noise process described by (Pang et al., 2018)

$\dot{z}_{r}(t)=-2 \pi f_{0} z_{r}(t)+2 \pi n_{0} \sqrt{G_{q}\left(n_{0}\right) v_{s}} w(t)$,

where $f_{0}$ is the lower cutoff frequency of the road profile, $n_{0}$ the reference spatial frequency, $G_{q}\left(n_{0}\right)$ a road roughness constant, and $w(t)$ white Gaussian noise with identity power spectral density (PSD) of zero mean. In this work, a class B road profile is chosen where $G_{q}\left(n_{0}\right)=64 \times 10^{-6} \mathrm{~m}^{-3}$ and $v_{s}=20 \mathrm{~m} / \mathrm{s}$. The displacement of the road input signal is shown in Figure 11. The time histories of $\left(z_{2}-z_{3}\right), \ddot{z}_{2}$ and $\ddot{z}_{1}$ are presented in Figures 16.

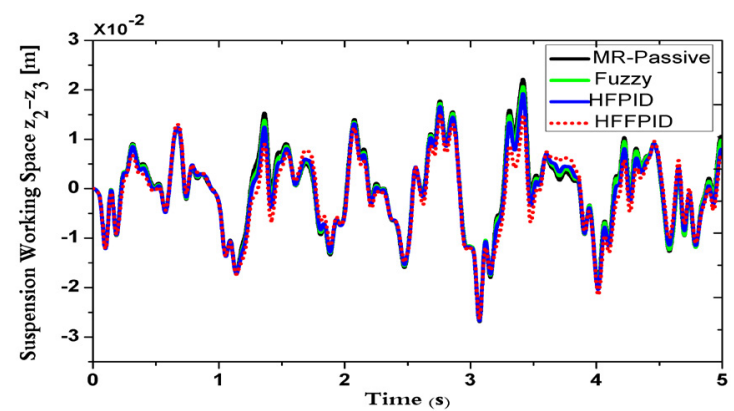

(a)

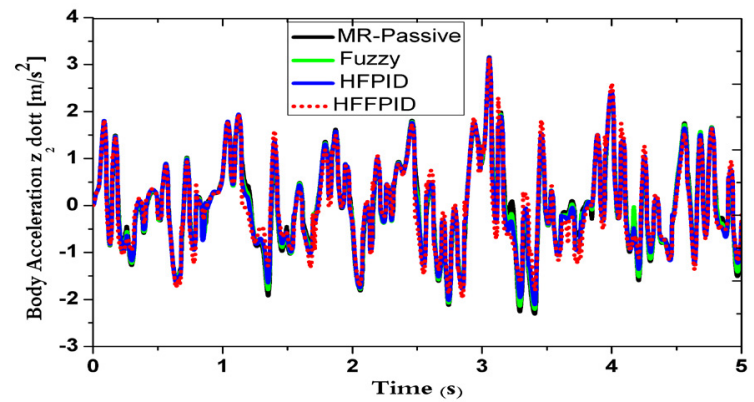

(b)

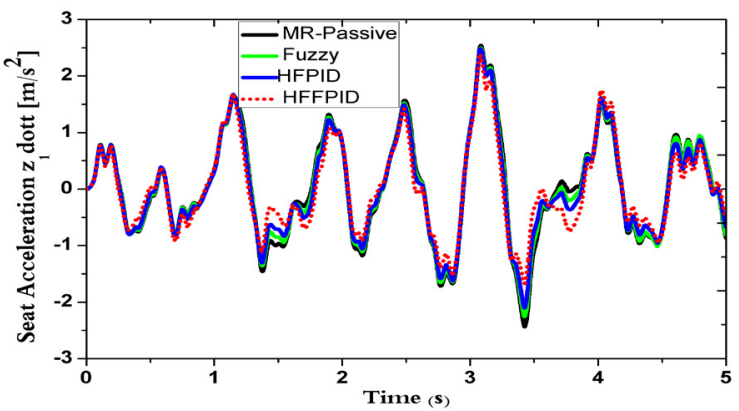

(c)

Figure 16. The time response of the system under RI excitation for (a) SWS,(b) BAC and(c) SAC 
Where in the cases of FLC, HFPID and HFFPID controllers the comparison of the actual damping control forces is provided in Figure 17. The simulation results prove the validity of the modified Bouc-Wen model of the MR damper once more. The relevant root mean square (RMS) values SWS, BAC and SAC for the semi-active suspension system controlled by HFPID , FLC controllers and MR passive suspension system are compared with those obtained for the HFFPID controlled system. The results are shown in Table 6 . The SWS reduced by $32.61 \%, 31.87 \%$ and $25.30 \%$, BAC reduced by $32.33 \%, 31.89 \%$ and $27.17 \%$, SAC is reduced by $40.85 \%, 37.58 \%$ and $31.14 \%$ compared to MR passive suspension system, FLC and HFPID, respectively. Specifically, it can be noticed from Table 6 that the proposed HFFPID controller has an overall good performance as compared to the others.

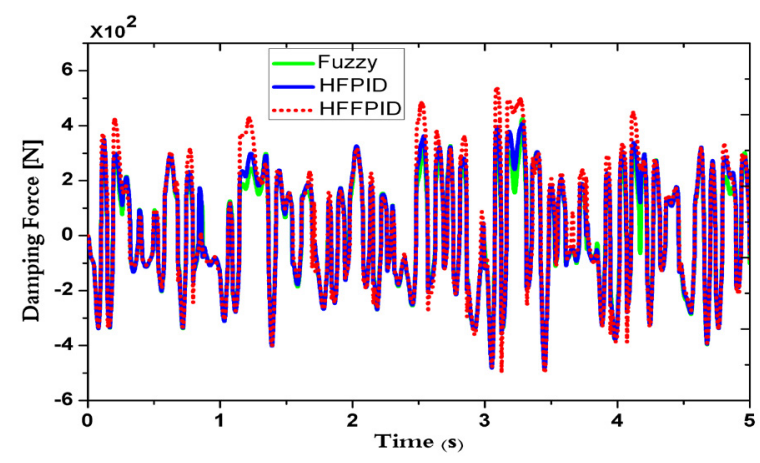

Figure 17. Damping forces for RI

\section{REFERENCES}

1. Choi, S.-B. \& Kim, W.-K. (2000). Vibration control of a semi-active suspension featuring electrorheological fluid dampers, Journal of Sound and vibration, 324(3), 537-546.

2. Dequan, S., Guili, G., Zhiwei, G. \& Peng, X. (2012). Application of expert fuzzy PID method for temperature control of heating furnace, Procedia Engineering, 29, 257-261.

3. Du, H. \& Zhang, N. (2007). Hळ control of active vehicle suspensions with actuator time delay, Journal of sound and vibration, 301(12), 236-252.

4. El-Kafafy, M., El-Demerdash, S. M. \& Rabeih, A.-A. M. (2012). Automotive ride comfort control using MR fluid damper, Engineering, 4(4), 179-87.

5. Guo, K.-H., Sui, J.-K. \& Guo, Y.-H. (2013). Semi-active control method for a high-speed railway vehicle lateral damper based on
Table 6. Percentage Reduction of the values of SWS, $\mathrm{BAC}$ and SAC for RI

\begin{tabular}{|c|c|c|c|}
\hline RMS & $\begin{array}{c}\text { HFFPID } \\
\text { with respect to } \\
\text { MR-Passive }\end{array}$ & $\begin{array}{c}\text { HFFPID } \\
\text { with respect } \\
\text { to Fuzzy }\end{array}$ & $\begin{array}{c}\text { HFFPID } \\
\text { with respect } \\
\text { to HFPID }\end{array}$ \\
\hline SWS & $32.61 \%$ & $31.87 \%$ & $25.30 \%$ \\
\hline BAC & $32.33 \%$ & $31.89 \%$ & $27.17 \%$ \\
\hline SAC & $40.85 \%$ & $37.58 \%$ & $31.14 \%$ \\
\hline
\end{tabular}

\section{Conclusion}

In present paper, a semi-active quarter car system with three degrees of freedom has been studied for bump and random road excitation. Its primary suspension is controlled by Fuzzy, HFPID and HFFPID controllers with the purpose of comparing the vehicle ride comfort in each case. The simulation responses in terms of PTP and RMS values show that Hybrid fuzzy-PID Controller with fuzzy selector (HFFPID) provides the best overall performance. It assures the best vehicle ride comfort in combination with a magneto-rheological shock absorber as part of the primary suspension system.

\section{Acknowledgments}

This research paper was funded by Natural Science Foundation of China Government, Grant (11472135) and Science Challenge Project, Grant (JCKY2016212A506-0104).

skyhook and groundhook hybrid damping, Zhendong yu Chongji (Journal of Vibration and Shock), 32(2), 18-22.

6. Hu, G., Liu, Q., Ding, R. \& Li, G. (2017). Vibration control of semi-active suspension system with magnetorheological damper based on hyperbolic tangent model, Advances in Mechanical Engineering, 9(5), 1687814017694581.

7. Johnson, M. A. \& Moradi, M. H. (2005). PID control. Springer.

8. Khodadadi, H. \& Ghadiri, H. (2018). Selftuning PID controller design using fuzzy logic for half car active suspension system, International Journal of Dynamics and Control, 6(1), 224-232.

9. Lai, C. Y. \& Liao, W.-H. (2002). Vibration control of a suspension system via a magnetorheological fluid damper, Modal Analysis, 8(4), 527-547. 
10. Lam, A. H.-F. \& Liao, W.-H. (2003). Semiactive control of automotive suspension systems with magneto-rheological dampers, International Journal of Vehicle Design, 33(1-3), 50-75.

11. Muniraj, R., Iruthayarajan, M. S. W. \& Arun, R. (2017). Tuning of robust PID controller with filter for SISO system using evolutionary algorithms, Studies in Informatics and Control, 26(3), 277-286. DOI: 10.24846/ v26i3y 201703

12. Mustafa, G. I., Wang, H. \& Tian, Y. (2019). Model-free Adaptive Fuzzy Logic Control for a Half-car Active Suspension System, Studies in Informatics and Control, 28(1), 13-24. DOI: 10.24846/v28i1y201902

13. Oliveira, K. F., César, M. B. \& Gonçalves, J. (2017). Fuzzy based control of a vehicle suspension system using a MR damper. In 12th Portuguese Conference on Automatic Control, Springer (pp. 571-581).

14. Paksoy, M., Guclu, R. \& Cetin, S. (2014). Semiactive self-tuning fuzzy logic control of full vehicle model with MR damper, Advances in Mechanical Engineering, 6, Article ID 816813.

15. Pang, H., Liu, F. \& Xu, Z. (2018). Variable universe fuzzy control for vehicle semiactive suspension system with MR damper combining fuzzy neural network and particle swarm optimization, Neurocomputing, 306, 130-140.

16. Pang, H., Zhang, X.\& Xu, Z.(2019). Adaptive backstepping-based tracking control design for nonlinear active suspension system with parameter uncertainties and safety constraints, ISA transactions, 88, 23-36.

17. Rashid, M., Hussain, M., Rahim, N. A. \& Momoh, J. (2007). Development of a semi-active car suspension control system using magneto-rheological damper model, International Journal of Mechanical and Materials Engineering, 2(2), 93-108.

18. Shanfa, L. S. Y. B. Y. \& Kongkang, L. Y. Z. (2006). Fuzzy-PID Switch Control on Semi-active Suspensions with MR Damper [J]. Transactions of the Chinese Society for Agricultural Machinery, 12.
19. Singh, D. \& Aggarwal, M. (2017). Passenger seat vibration control of a semi-active quarter car system with hybrid Fuzzy-PID approach, International Journal of Dynamics and Control, 5(2), 287-296.

20. Song, S. \& Liu, W. (2006). Fuzzy parameters self-tuning PID control of switched reluctance motor based on Simulink/NCD. In 2006 International Conference on Computational Inteligence for Modelling Control and Automation and International Conference on Intelligent Agents Web Technologies and International Commerce (CIMCA'06) (pp. 73-73). IEEE.

21. Spencer, B. F., Dyke, S. J., Sain, M. K. \& Carlson, J. D. (1997). Phenomenological model for magnetorheological dampers, Journal of engineering mechanics, 123(3), 230-238.

22. Wang, X. (2018). Semi-active adaptive optimal control of vehicle suspension with a magnetorheological damper based on policy iteration, Journal of Intelligent Material Systems and Structures, 29(2), 255-264.

23. Wen, Y. (1976). Method for random vibration of hysteretic systems, Journal of the engineering mechanics division, 102(2), 249-263.

24. Yin, X., Zhang, L., Zhu, Y., Wang, C. \& Li, Z. (2016). Robust control of networked systems with variable communication capabilities and application to a semi-active suspension system, IEEE/ASME Transactions on Mechatronics, 21(4), 2097-2107.

25. Ying, Z., Zhu, W. \& Soong, T. (2003). A stochastic optimal semi-active control strategy for ER/MR dampers, Journal of Sound and Vibration, 259(1), 45-62.

26. Zhang, J., Wang, N. \& Wang, S. (2004). A developed method of tuning PID controllers with fuzzy rules for integrating processes. In Proceedings of the 2004 American Control Conference (pp. 1109-1114). IEEE.

27. Zimmermann, H.-J. (2011). Fuzzy set theory - and its applications, $4^{\text {th }}$ Edition. Springer Seience + Business Media New York. 